\title{
Associations of Smoking and Alcohol and Coffee Intake with Fracture and Bone Mineral Density: A Mendelian Randomization Study
}

\author{
Shuai Yuan ${ }^{1} \cdot$ Karl Michaëlsson ${ }^{1} \cdot$ Zihao Wan $^{2} \cdot$ Susanna C. Larsson ${ }^{1}$
}

Received: 16 July 2019 / Accepted: 22 August 2019 / Published online: 4 September 2019

(c) The Author(s) 2019

\begin{abstract}
The causal associations of smoking and alcohol and coffee intake with fracture and bone mineral density are unknown. We investigated the associations using Mendelian randomization (MR). Summary-level data from UK Biobank for bone fractures (main outcome) (53,184 cases; 373,611 non-cases) and estimated bone mineral density (eBMD) ( $n=426,824$ individuals) were used. Single-nucleotide polymorphisms associated with smoking initiation $(n=378)$ and alcohol $(n=99)$ and coffee $(n=15)$ intake at the genome-wide significance threshold $\left(P=5 \times 10^{-8}\right)$ were identified from published genome-wide association studies. Univariable and multivariable inverse-variance weighted, weighted median, MR-Egger, and MR-PRESSO methods were used for statistical analyses. Genetic predisposition to smoking initiation was associated with fracture but not eBMD. The odds ratio of fracture per one-unit increase in log odds of smoking was 1.09 (95\% confidence interval 1.04, 1.15; $P=8.58 \times 10^{-4}$ ) after adjustment for alcohol intake in the multivariable MR analysis. The association remained in complementary analyses. Genetically predicted alcohol and coffee intake was not associated with fracture or eBMD. Nevertheless, genetic liability to alcohol dependence, based on variants in the $A L D 1 B$ gene, was associated with fracture and lower eBMD. The odds ratio was $1.06(95 \%$ confidence interval $1.01,1.12 ; P=0.018)$ per genetically predicted one-unit higher log odds of liability to alcohol dependence. This MR study strengthens the causal inference on an association between smoking and higher fracture risk but found no linear association of modestly higher alcohol and coffee intake with fracture or BMD. However, alcohol dependence may increase fracture risk.
\end{abstract}

Keywords Alcohol $\cdot$ Bone mineral density $\cdot$ Coffee $\cdot$ Fracture $\cdot$ Mendelian randomization $\cdot$ Smoking

Abbreviations
BMD Bone mineral density
BMI Body mass index

Electronic supplementary material The online version of this article (https://doi.org/10.1007/s00223-019-00606-0) contains supplementary material, which is available to authorized users.

Susanna C. Larsson

susanna.larsson@surgsci.uu.se

Shuai Yuan

shuai.yuan@stud.ki.se

Karl Michaëlsson

karl.michaelsson@surgsci.uu.se

Zihao Wan

jason_wanzh@link.cuhk.edu.hk

1 Department of Surgical Sciences, Uppsala University, The EpiHub, MTC-huset, 75185 Uppsala, Sweden

2 Department of Orthopaedics and Traumatology, Faculty of Medicine, The Chinese University of Hong Kong, Shatin, Hong Kong
CI Confidence interval

DXA Dual-energy X-ray absorptiometry

eBMD Estimated bone mineral density

MR Mendelian randomization

OR Odds ratio

SNPs Single-nucleotide polymorphisms

\section{Background}

Cigarette smoking, and alcohol and coffee intake are potential modifiable risk factors for fracture. Meta-analyses of longitudinal studies have shown that smoking has a dose-response-related negative impact on bone loss [1] and is associated with an increased risk of fracture $[2,3]$ which is reduced after smoking cessation [4]. Smoking also confers higher risk of certain complications after fracture [5]. However, whether bone mineral density (BMD) plays a causal mediating role in the pathway between smoking and fracture is unproven $[3,6]$. 
Available evidence on the detrimental effect of heavy alcohol intake on BMD and fracture is consistent [7, 8], but studies investigating the bone-related health effect of light alcohol drinking [7-10] are inconclusive. Likewise, the potential role of coffee intake for fracture risk is unclear [11]. In addition, whether these associations are causal is unknown because observational studies are less likely to fully control for residual confounding and reverse causality.

Exploiting genetic variants as instrumental variables for exposures in Mendelian randomization (MR) study strengthens the causal inference on an exposure-outcome association [12]. This method minimizes confounding since genetic variants are randomly assorted at concept, thereby having no relevance to self-selected lifestyle factors and behaviors. It overcomes reverse causality as allelic randomization precedes the development of disease.

We conducted an MR study to assess the associations of smoking, alcohol intake, and habitual coffee intake with fracture risk as the primary analyses. To investigate whether BMD may mediate the associations, we also assessed the associations of these genetically predicted exposures with BMD in secondary analyses.

\section{Methods}

\section{Study Design}

This MR study is based on summary-level data from the largest published genome-wide association studies (GWASs) on smoking initiation (ever smoked regularly), alcohol and coffee intake, fracture, and eBMD. Detailed information on the GWASs and SNPs used as instrumental variables is presented in S Table 1, S Table 2, S Table 3, and S Table 4. The analyses have been approved by the Swedish Ethical Review Authority.

\section{Source of Outcomes}

Summary-level genetic data for fractures and estimated bone mineral density (eBMD), derived from heel quantitative ultrasound, were obtained from publicly available data based on the UK Biobank cohort [13]. The fracture genome-wide association study included 416,795 individuals of European ancestry $(53,184$ cases and 373,611 non-cases). Fracture cases were collected by using two mutually non-exclusive methods: Hospital Episodes Statistics and questionnaire-based self-reported fracture in GWAS. The 10th revision of International Classification of Diseases (ICD10) codes was used to define fracture cases (S Table 5). Excluded were fractures of the skull, face, hands and feet, pathological fractures due to malignancy, atypical femoral fractures, periprosthetic fractures, and healed fracture codes [13]. eBMD was used as a proxy of BMD [14] and was based on 426,824 white British individuals, 38-76 years of age (mean age 57 years). We complemented the eBMD data by summary-level data for forearm, femoral neck, and lumbar spine BMD derived from dual-energy X-ray absorptiometry (DXA). The GWAS datasets for DXA-derived BMD included 32,965 individuals of European ancestry [15].

\section{SNPs Selection}

For smoking initiation, 378 single-nucleotide polymorphisms (SNPs) were identified as instrumental variables at the genome-wide significance level $\left(P<5.0 \times 10^{-8}\right)$ from a recent genome-wide association study of 1,232,091 individuals of European ancestry [16]. Four and thirteen SNPs were unavailable in the fracture and eBMD dataset, respectively. After using proxy SNPs found in National Cancer Institute LDlink database $\left(R^{2}>0.7\right), 377$ and 376 smoking-related SNPs of fracture and eBMD were selected as instrumental variables.

SNPs associated with alcohol intake were identified as instrumental variables at the genome-wide significance level from a genome-wide association study of 941,280 individuals of European descents [16]. Ninety-six SNPs for fracture (three missing) and ninety-three SNPs for eBMD (six missing) were available. Three proxy SNPs for missing SNPs were identified by a search in the National Cancer Institute LDlink database $\left(R^{2}>0.9\right)$. In total, ninety-nine and ninety-six alcohol intake-related SNPs were constructed as instrumental variables for fracture and eBMD. There was a moderately strong genetic correlation between smoking initiation and alcohol intake $\left(r_{\mathrm{g}}=0.34\right)$ [16].

As a complementary analysis to alcohol intake, we considered three SNPs associated with liability to alcohol dependence at the genome-wide significance level $\left(P<5 \times 10^{-8}\right)$ in a genome-wide association study of 46,568 individuals (11,569 cases and 34,999 controls) of European ancestry [17]. One of the SNPs was not available in the fracture dataset, and two SNPs were unavailable in the eBMD and DXA-derived BMD datasets. No suitable proxies for those SNPs were found, leaving two SNPs [rs1229984 and rs 3811802 (pairwise $R^{2}=0.001$ ) in the $A D H 1 B$ gene] in the analysis of fracture, one SNP (rs 1229984) in the analysis of eBMD, and one SNP (rs3811802) in the analyses of DXAderived BMD.

Fifteen SNPs robustly associated with coffee intake at the genome-wide significance level were obtained from the most recent and largest genome-wide association study on habitual coffee intake [18]. The study included 375,833 individuals of European ancestry from the UK Biobank [18]. All SNPs were available in the fracture and eBMD datasets. 


\section{Statistical Analyses}

We used different MR methods with distinct strengths and assumptions. The inverse-variance weighted method (under random-effects model) was used for the main analyses, and weighted median, MR-Egger regression, and MR-PRESSO for the sensitivity analyses. The inverse-variance weighted method estimates the associations most precisely but is sensitive to invalid instrumental variables with pleiotropic effects [19]. The weighted median approach provides a consistent estimate under the prerequisite that $\geq 50 \%$ of the weight in the analysis comes from valid instrumental variables [20]. The MR-Egger regression method can identify and correct for directional pleiotropy but has low power [21]. The MR pleiotropy residual sum and outlier (MR-PRESSO) test was used to detect possible outliers [22]. Results obtained from the MR-PRESSO analysis are corrected for horizontal pleiotropy via outlier removal. MR-PRESSO distortion test aims at testing the differences between the causal estimates before and after outlier correction. Multivariable MR analyses were conducted to eliminate the mutual influence of smoking and alcohol drinking [23], by adjusting for genetic predisposition to smoking in the analysis of alcohol intake, and for genetically predicted alcohol intake in the analysis of smoking. In sensitivity analyses of coffee intake, three SNPs (rs574367, rs10865548, and rs66723169) were excluded due to genome-wide significant association with body mass index identified through a search in the PhenoScanner V2 database [24].

The odds ratios (ORs) of fracture were scaled to one-unit increase in genetically predicted smoking (expressed as log odds of ever smoked regularly) or alcohol intake (expressed as standard deviations of log-transformed drinks per week) and per $50 \%$ change in cups of coffee consumed per day. For eBMD, the results represent the change in $\mathrm{g} / \mathrm{cm}^{2}$ for a unit increment of genetically predicted smoking or alcohol intake and $50 \%$ change in cups of coffee consumed per day. Associations with $P$ values below 0.017 (where $P=0.05 / 3$ ) were deemed statistically significant after Bonferroni correction for three exposures. $P$ values between 0.017 and 0.05 were regarded as suggestive evidence of associations. All $P$ values were two-sided, and all statistical analyses were performed in Stata/SE 15.0 [25] and R software [26]. Statistical power was calculated using a web-based application [27].

\section{Results}

\section{Smoking, Alcohol and Coffee Intake, and Fracture}

We had over $90 \%$ statistical power to detect an OR of 0.9 (or 1.1 ) and $100 \%$ statistical power to detect an OR of 0.8 (or 1.2) for smoking initiation (S Table 6). Genetically predicted smoking initiation was associated with higher odds of fracture in all analyses, except for the MR-Egger regression analysis with a borderline significant association (Fig. 1). The OR of fracture per one-unit increase of smoking was 1.09 (95\% confidence interval $(\mathrm{CI}), 1.04,1.15 ; P=2.43 \times 10^{-4}$ ) in analysis using the random-effects inverse-variance weighted model corrected for heterogeneity between individual SNPs $\left(I^{2}=35 \% ; P<0.0001\right)$ (Fig. 1$)$. The MR-PRESSO test detected two outliers among included SNPs, but there was no significant difference between the casual estimates before and after correction for outliers $(P$ of distortion test $=0.747)$.

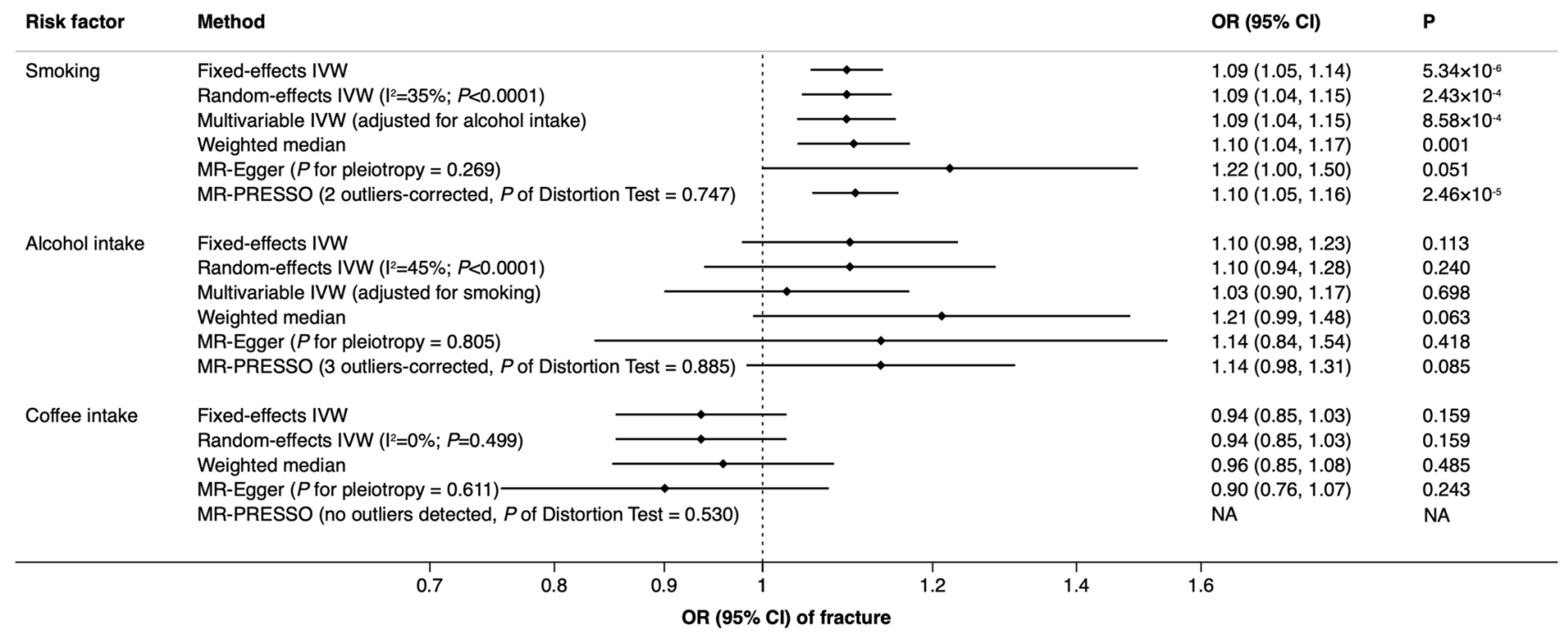

Fig. 1 Associations of smoking and alcohol and coffee intake with fracture risk in Mendelian randomization analyses. CI confidence interval, $I V W$ inverse-variance weighted, MR-Egger Mendelian rand-
omization-Egger, MR-PRESSO Mendelian randomization pleiotropy residual sum and outlier, $O R$ odds ratio 
The association remained statistically significant after multivariable adjustment for alcohol intake $(\mathrm{OR}=1.09 ; 95 \% \mathrm{CI}$ $1.04,1.15 ; P=8.58 \times 10^{-4}$ ) (Fig. 1).

Genetically predicted alcohol intake and coffee intake were not associated with the odds of fracture in any MR analyses, but the statistical power to detect weak associations was low (10\% and $31 \%$ power to detect an OR of 0.9 (or 1.1) for alcohol and coffee intake, respectively). There was no indication of directional pleiotropy in the MR-Egger analysis $(P=0.805$ for alcohol intake and $P=0.611$ for coffee intake). The lack of association between genetically predicted coffee intake and fracture persisted after excluding the BMI-related SNPs (S Figure 1). Genetic liability to alcohol dependence was associated with higher odds of fracture. The OR was 1.06 (95\% CI 1.01, 1.12; $P=0.018$ ) per genetically predicted one-unit higher log odds of liability to alcohol dependence.

\section{Smoking, Alcohol and Coffee Intake, and eBMD}

Genetically predicted smoking initiation, alcohol, and coffee intake were not associated with eBMD in the random-effects inverse-variance weighted method with substantive heterogeneity among SNPs (all $P<0.0001)$ (Fig. 2). After adjustment for potential pleiotropy and outliers, the null associations remained for smoking and alcohol intake, whereas there was a suggestive positive association between coffee intake and eBMD (beta $=0.07 \mathrm{~g} / \mathrm{cm}^{2} ; 95 \%$ CI $0.01,0.13$; $P=0.026$ ) (Fig. 2). No association between coffee intake and eBMD was found after exclusion of the three SNPs with pleiotropic associations with BMI (S Figure 1). Genetically predicted smoking initiation and alcohol and coffee intake were not associated with DXA-derived BMD at forearm, femoral neck, or lumbar spine (S Table 7). Genetic liability to alcohol dependence was associated with lower eBMD but was not associated with forearm, femoral neck, or lumbar spine BMD (all $P>0.46$ ). The difference in eBMD in $\mathrm{g} / \mathrm{cm}^{2}$ was $-0.049\left(95 \% \mathrm{CI}-0.066,-0.032 ; P=5.60 \times 10^{-10}\right)$ per genetically predicted one-unit higher log odds of liability to alcohol dependence.

\section{Discussion}

In this first MR study of smoking, and alcohol and coffee intake in relation to fracture and BMD, genetically predicted smoking initiation was significantly associated with higher odds of fracture but was not associated with eBMD. Genetically predicted alcohol intake and coffee assumption were not associated with either fracture or eBMD. Nevertheless, genetic liability to alcohol dependence, based on one or two SNPs in the $A D H I B$ gene, was associated with higher odds of fracture and lower eBMD.

Observational studies have documented a bone detrimental effect of cigarette smoking in both men [6] and women [28]. Compared with never smokers, current and past smokers had an increased risk of fracture [6,28], which is in line with results of the present study. However, this MR study did not support observational data showing an association between smoking and lower BMD. A systematic review pooling 86 cross-sectional and longitudinal studies concluded that smoking was risk factor for BMD, thereby theoretically increasing the risk of fracture [1]. Some limitations in this meta-analysis may subordinate the validity and bias

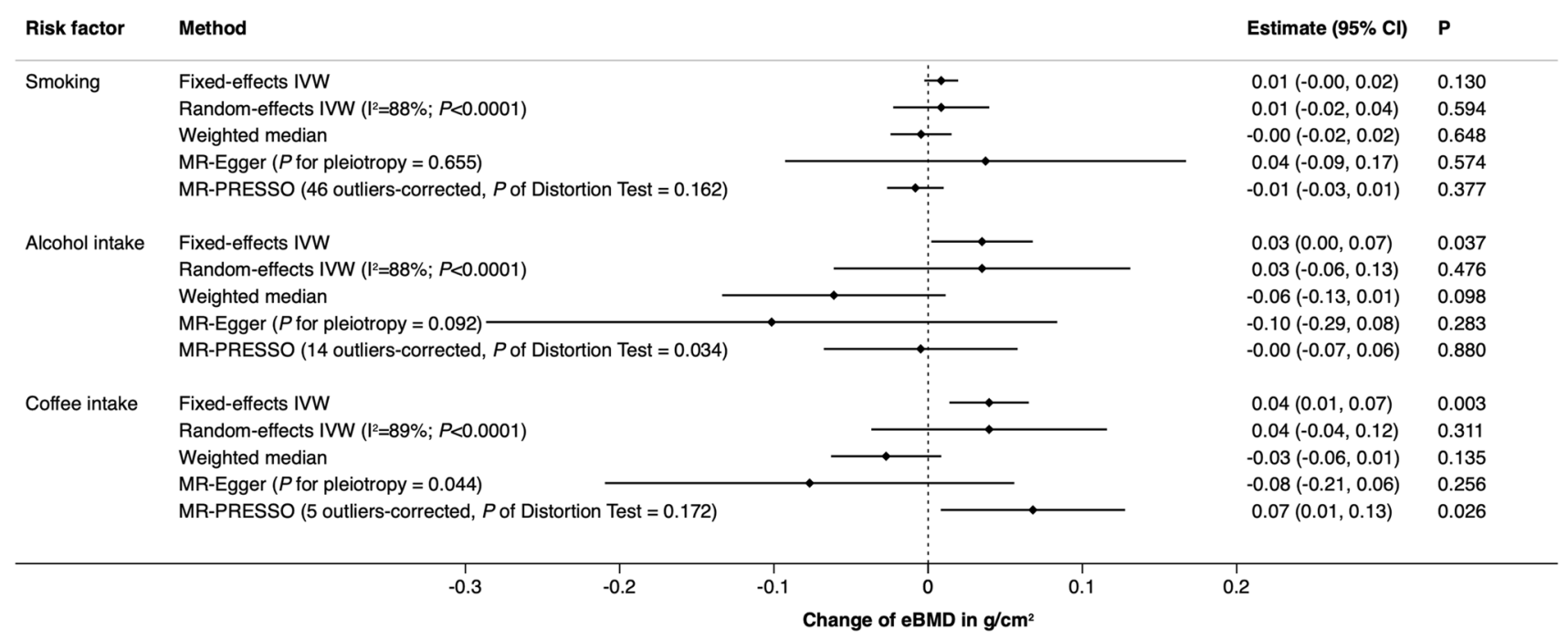

Fig. 2 Associations of smoking and alcohol and coffee intake with estimated bone mineral density $\left(\mathrm{g} / \mathrm{cm}^{2}\right)$ in Mendelian randomization analyses. $C I$ confidence interval, $e B M D$ estimated bone mineral density, $I V W$ inverse-variance weighted, MR-Egger Mendelian randomization-Egger, MR-PRESSO Mendelian randomization pleiotropy residual sum and outlier, $O R$ odds ratio 
the results, such as residual confounding, reverse causality, and heterogeneity between included studies. Hence, it has been speculated that BMD may not play a major role in the causal pathway between cigarette smoking and fracture [3]. Further studies are needed to verify this novel finding.

The effect of smoking on bone metabolism and pathology of osteoporosis is not fully understood. Smoking might affect bone quality independent of factors captured by measurement of areal BMD, and these factors may, for example, include bone size, trabecular connectivity, and bone strength. There are several plausible mechanisms of direct adverse effect of smoking on bone, such as nuclear factor kappaB pathway activation [29], collagen metabolism [30], and bone angiogenesis [31]. Clinical studies have indicated that an increased smoking exposure suppresses osteoprotegerin production [32] and increases soluble receptor activator of nuclear factor kappa-B ligand concentration via kappa-B pathway activation [29]. Inflammation and oxidative stress induced by cigarette smoking damage collagen metabolism [33], which is a vital biochemical marker of bone metabolism [34]. In addition, smoking can directly exert toxicity on bone cells [33, 35] and increase calcitonin resistance [36], which impedes bone angiogenesis [31].

Most observational studies have found a detrimental effect of heavy alcohol intake, but a protective effect of light or moderate alcohol intake on fracture risk [9]. Thus, a $\mathrm{J}$-shaped association of alcohol intake with fracture risk has been proposed. No association was detected between genetically predicted alcohol intake and fracture risk in the present study. However, we found that genetic variations in the $A D H 1 B$ gene, which is associated with both alcohol intake and alcohol dependence, were associated with higher odds of fracture as well as lower eBMD. This finding may suggest that heavy but not moderate drinking increases fracture risk.

As for the effect of coffee intake on fracture risk, results of the present MR study are in line with most observational studies. A systemic review including 14 studies with 9958 fracture cases and 186,034 controls found no significant association between coffee intake and the risk of hip fracture [11]. However, results of other meta-analyses have shown that coffee intake is associated with an increased risk of fractures in women but with a decreased risk in men [37]. A large cohort study of Swedish women did not support a positive association between coffee intake, assessed with repeated food-frequency questionnaires and after adjustment for confounders, and risk of fracture ( $n=14,738$ cases) [24]. Further studies are needed to test the sex difference on the association between coffee intake and fracture risk.

There are several strengths of this study. The MR study design minimized residual confounding and reverse causality that potentially exist in conventional observational studies. We reduced possible bias due to population stratification by restricting the study population to individuals of
European descent. A major limitation is that the statistical power was low in the analyses of alcohol and coffee intake. Hence, this study was unable to detect weak associations with those exposures. A nonlinear relationship between alcohol intake and fracture was not able to be tested as a linear assumption between exposure and outcome was assumed in the MR analysis based on summary-level data. Another limitation is that participants from the UK Biobank were included in the genome-wide association studies of both the exposures and the outcomes. This sample overlap may have resulted in type 1 error, and we can therefore not rule out that the observed association between smoking and fracture was a false positive finding.

\section{Conclusions}

This study, by use of genetic instruments, strengthens the causal inference on an association between smoking and higher fracture risk. Accordingly, by more firm scientific support, reducing cigarette smoking initiation and smoking cessation, considering the reversible risk of smoking on fracture risk $[38,39]$, can now be even more strongly recommended for fracture prevention. No associations were observed between genetically predicted alcohol and coffee intake and fracture or BMD, but there was evidence that alcohol dependence may be a risk factor for fracture. Largescale causal inference studies focusing on nonlinear relationships of alcohol intake and sex difference for coffee intake with fracture risk are warranted.

Acknowledgements Open access funding provided by Uppsala University. The authors thank the GEnetic Factors for OSteoporosis (GEFOS) Consortium for providing summary-level data on fracture and eBMD.

Author's Contribution SY, SCL, and KM designed the study. SY and SCL analyzed the data. SY drafted the manuscript. SY, KM, ZW, and SCL interpreted the data and critically reviewed the manuscript.

Data Availability All data included in this study were uploaded as supplements and also publicly available in published GWASs and open GWAS datasets.

\section{Compliance with Ethical Standards}

Conflict of interest No specific funding was available for this study. Shuai Yuan, Karl Michaëlsson, Zihao Wan and Susanna C. Larsson declares no relevant conflicts of interest to disclose.

Human and Animal Rights and Informed Consent All participants of the original studies included in the GWASs had provided informed consent.

Open Access This article is distributed under the terms of the Creative Commons Attribution 4.0 International License (http://creat ivecommons.org/licenses/by/4.0/), which permits unrestricted use, 
distribution, and reproduction in any medium, provided you give appropriate credit to the original author(s) and the source, provide a link to the Creative Commons license, and indicate if changes were made.

\section{References}

1. Ward KD, Klesges RC (2001) A meta-analysis of the effects of cigarette smoking on bone mineral density. Calcif Tissue Int 68:259-270

2. Vestergaard P, Mosekilde L (2003) Fracture risk associated with smoking: a meta-analysis. J Intern Med 254:572-583

3. Kanis JA, Johnell O, Oden A, Johansson H, De Laet C, Eisman JA, Fujiwara S, Kroger H, McCloskey EV, Mellstrom D, Melton LJ, Pols H, Reeve J, Silman A, Tenenhouse A (2005) Smoking and fracture risk: a meta-analysis. Osteoporos Int 16:155-162

4. Olofsson H, Byberg L, Mohsen R, Melhus H, Lithell H, Michaëlsson K (2005) Smoking and the risk of fracture in older men. J Bone Miner Res 20:1208-1215

5. Gronkjaer M, Eliasen M, Skov-Ettrup LS, Tolstrup JS, Christiansen AH, Mikkelsen SS, Becker U, Flensborg-Madsen T (2014) Preoperative smoking status and postoperative complications: a systematic review and meta-analysis. Ann Surg 259:52-71

6. Jutberger H, Lorentzon M, Barrett-Connor E, Johansson H, Kanis JA, Ljunggren O, Karlsson MK, Rosengren BE, Redlund-Johnell I, Orwoll E, Ohlsson C, Mellstrom D (2010) Smoking predicts incident fractures in elderly men: Mr OS Sweden. J Bone Miner Res 25:1010-1016

7. Maurel DB, Boisseau N, Benhamou CL, Jaffre C (2012) Alcohol and bone: review of dose effects and mechanisms. Osteoporos Int 23:1-16

8. Zhang X, Yu Z, Yu M, Qu X (2015) Alcohol consumption and hip fracture risk. Osteoporos Int 26:531-542

9. Berg KM, Kunins HV, Jackson JL, Nahvi S, Chaudhry A, Harris KA Jr, Malik R, Arnsten JH (2008) Association between alcohol consumption and both osteoporotic fracture and bone density. Am J Med 121:406-418

10. Mukamal KJ, Robbins JA, Cauley JA, Kern LM, Siscovick DS (2007) Alcohol consumption, bone density, and hip fracture among older adults: the cardiovascular health study. Osteoporos Int 18:593-602

11. Sheng J, Qu X, Zhang X, Zhai Z, Li H, Liu X, Liu G, Zhu Z, Hao Y, Qin A, Dai K (2014) Coffee, tea, and the risk of hip fracture: a meta-analysis. Osteoporos Int 25:141-150

12. Larsson SC, Michaelsson K, Burgess S (2018) Mendelian randomization in the bone field. Bone 126:51-58

13. Morris JA, Kemp JP, Youlten SE, Laurent L, Logan JG, Chai RC, Vulpescu NA, Forgetta V, Kleinman A, Mohanty ST, Sergio CM, Quinn J, Nguyen-Yamamoto L, Luco AL, Vijay J, Simon MM, Pramatarova A, Medina-Gomez C, Trajanoska K, Ghirardello EJ, Butterfield NC, Curry KF, Leitch VD, Sparkes PC, Adoum AT, Mannan NS, Komla-Ebri DSK, Pollard AS, Dewhurst HF, Hassall TAD, Beltejar MG, Adams DJ, Vaillancourt SM, Kaptoge S, Baldock P, Cooper C, Reeve J, Ntzani EE, Evangelou E, Ohlsson C, Karasik D, Rivadeneira F, Kiel DP, Tobias JH, Gregson CL, Harvey NC, Grundberg E, Goltzman D, Lelliott CJ, Hinds DA, Ackert-Bicknell CL, Hsu YH, Maurano MT, Croucher PI, Williams GR, Bassett JHD, Evans DM, Richards JB (2019) An atlas of genetic influences on osteoporosis in humans and mice. Nat Genet 51:258-266

14. Karasik D, Myers RH, Hannan MT, Gagnon D, McLean RR, Cupples LA, Kiel DP (2002) Mapping of quantitative ultrasound of the calcaneus bone to chromosome 1 by genome-wide linkage analysis. Osteoporos Int 13:796-802
15. Zheng HF, Forgetta V, Hsu YH, Estrada K, Rosello-Diez A, Leo PJ, Dahia CL, Park-Min KH, Tobias JH, Kooperberg C, Kleinman A, Styrkarsdottir U, Liu CT, Uggla C, Evans DS, Nielson CM, Walter K, Pettersson-Kymmer U, McCarthy Eriksson J, Kwan T, Jhamai M, Trajanoska K, Memari Y, Min J, Huang J, Danecek P, Wilmot B, Li R, Chou WC, Mokry LE, Moayyeri A, Claussnitzer M, Cheng CH, Cheung W, Medina-Gómez C, Ge B, Chen SH, Choi K, Oei L, Fraser J, Kraaij R, Hibbs MA, Gregson CL, Paquette D, Hofman A, Wibom C, Tranah GJ, Marshall M, Gardiner BB, Cremin K, Auer P, Hsu L, Ring S, Tung JY, Thorleifsson G, Enneman AW, van Schoor NM, de Groot LC, van der Velde N, Melin B, Kemp JP, Christiansen C, Sayers A, Zhou Y, Calderari S, van Rooij J, Carlson C, Peters U, Berlivet S, Dostie J, Uitterlinden AG, Williams SR, Farber C, Grinberg D, LaCroix AZ, Haessler J, Chasman DI, Giulianini F, Rose LM, Ridker PM, Eisman JA, Nguyen TV, Center JR, Nogues X, Garcia-Giralt N, Launer LL, Gudnason V, Mellström D, Vandenput L, Amin N, van Duijn CM, Karlsson MK, Ljunggren Ö, Svensson O, Hallmans G, Rousseau F, Giroux S, Bussière J, Arp PP, Koromani F, Prince RL, Lewis JR, Langdahl BL, Hermann AP, Jensen JE, Kaptoge S, Khaw KT, Reeve J, Formosa MM, Xuereb-Anastasi A, Akesson K, McGuigan FE, Garg G, Olmos JM, Zarrabeitia MT, Riancho JA, Ralston SH, Alonso N, Jiang X, Goltzman D, Pastinen T, Grundberg E, Gauguier D, Orwoll ES, Karasik D, Davey-Smith G, AOGC Consortium, Smith AV, Siggeirsdottir K, Harris TB, Zillikens MC, van Meurs JB, Thorsteinsdottir U, Maurano MT, Timpson NJ, Soranzo N, Durbin R, Wilson SG, Ntzani EE, Brown MA, Stefansson K, Hinds DA, Spector T, Cupples LA, Ohlsson C, Greenwood CM, UK10 K Consortium, Jackson RD, Rowe DW, Loomis CA, Evans DM, Ackert-Bicknell CL, Joyner AL, Duncan EL, Kiel DP, Rivadeneira F, Richards JB (2015) Whole-genome sequencing identifies EN1 as a determinant of bone density and fracture. Nature 526(7571):112-117

16. Liu M, Jiang Y, Wedow R, Li Y, Brazel DM, Chen F, Datta G, Davila-Velderrain J, McGuire D, Tian C, Zhan X, Choquet H, Docherty AR, Faul JD, Foerster JR, Fritsche LG, Gabrielsen ME, Gordon SD, Haessler J, Hottenga JJ, Huang H, Jang SK, Jansen PR, Ling Y, Magi R, Matoba N, McMahon G, Mulas A, Orru V, Palviainen T, Pandit A, Reginsson GW, Skogholt AH, Smith JA, Taylor AE, Turman C, Willemsen G, Young H, Young KA, Zajac GJM, Zhao W, Zhou W, Bjornsdottir G, Boardman JD, Boehnke M, Boomsma DI, Chen C, Cucca F, Davies GE, Eaton $\mathrm{CB}$, Ehringer MA, Esko T, Fiorillo E, Gillespie NA, Gudbjartsson DF, Haller T, Harris KM, Heath AC, Hewitt JK, Hickie IB, Hokanson JE, Hopfer CJ, Hunter DJ, Iacono WG, Johnson EO, Kamatani Y, Kardia SLR, Keller MC, Kellis M, Kooperberg C, Kraft P, Krauter KS, Laakso M, Lind PA, Loukola A, Lutz SM, Madden PAF, Martin NG, McGue M, McQueen MB, Medland SE, Metspalu A, Mohlke KL, Nielsen JB, Okada Y, Peters U, Polderman TJC, Posthuma D, Reiner AP, Rice JP, Rimm E, Rose RJ, Runarsdottir V, Stallings MC, Stancakova A, Stefansson H, Thai KK, Tindle HA, Tyrfingsson T, Wall TL et al (2019) Association studies of up to 1.2 million individuals yield new insights into the genetic etiology of tobacco and alcohol use. Nat Genet 51:237-244

17. Walters RK, Polimanti R, Johnson EC, McClintick JN, Adams MJ, Adkins AE, Aliev F, Bacanu SA, Batzler A, Bertelsen S, Biernacka JM, Bigdeli TB, Chen LS, Clarke TK, Chou YL, Degenhardt F, Docherty AR, Edwards AC, Fontanillas P, Foo JC, Fox L, Frank J, Giegling I, Gordon S, Hack LM, Hartmann AM, Hartz SM, Heilmann-Heimbach S, Herms S, Hodgkinson C, Hoffmann P, Jan Hottenga J, Kennedy MA, Alanne-Kinnunen M, Konte B, Lahti J, Lahti-Pulkkinen M, Lai D, Ligthart L, Loukola A, Maher BS, Mbarek H, McIntosh AM, McQueen MB, Meyers JL, Milaneschi Y, Palviainen T, Pearson JF, Peterson RE, Ripatti S, Ryu E, Saccone NL, Salvatore JE, Sanchez-Roige S, Schwandt M, Sherva 
R, Streit F, Strohmaier J, Thomas N, Wang JC, Webb BT, Wedow R, Wetherill L, Wills AG, 23andMe Research Team, Boardman JD, Chen D, Choi DS, Copeland WE, Culverhouse RC, Dahmen N, Degenhardt L, Domingue BW, Elson SL, Frye MA, Gäbel W, Hayward C, Ising M, Keyes M, Kiefer F, Kramer J, Kuperman S, Lucae S, Lynskey MT, Maier W, Mann K, Männistö S, MüllerMyhsok B, Murray AD, Nurnberger JI, Palotie A, Preuss U, Räikkönen K28, Reynolds MD, Ridinger M, Scherbaum N, Schuckit MA, Soyka M, Treutlein J, Witt S, Wodarz N, Zill P, Adkins DE, Boden JM25, Boomsma DI, Bierut LJ, Brown SA, Bucholz KK, Cichon S, Costello EJ, de Wit H, Diazgranados N, Dick DM, Eriksson JG, Farrer LA, Foroud TM, Gillespie NA, Goate AM, Goldman D, Grucza RA, Hancock DB, Harris KM, Heath AC, Hesselbrock V, Hewitt JK, Hopfer CJ, Horwood J, Iacono W, Johnson EO, Kaprio JA, Karpyak VM, Kendler KS, Kranzler HR, Krauter K, Lichtenstein P, Lind PA, McGue M, MacKillop J, Madden PAF, Maes HH, Magnusson P, Martin NG, Medland SE20, Montgomery GW, Nelson EC, Nöthen MM, Palmer AA, Pedersen NL, Penninx BWJH, Porjesz B, Rice JP, Rietschel M, Riley BP, Rose R, Rujescu D, Shen PH, Silberg J, Stallings MC, Tarter RE, Vanyukov MM, Vrieze S, Wall TL, Whitfield JB, Zhao H, Neale BM, Gelernter J, Edenberg HJ, Agrawal A (2018) Transancestral GWAS of alcohol dependence reveals common genetic underpinnings with psychiatric disorders. Nat Neurosci 21(12): 1656

18. Zhong VW, Kuang A, Danning RD, Kraft P, van Dam RM, Chasman DI, Cornelis MC (2019) A genome-wide association study of bitter and sweet beverage consumption. Hum Mol Genet 28:2449-2457

19. Burgess S, Bowden J, Fall T, Ingelsson E, Thompson SG (2017) Sensitivity analyses for robust causal inference from Mendelian randomization analyses with multiple genetic variants. Epidemiology $28: 30-42$

20. Bowden J, Davey Smith G, Haycock PC, Burgess S (2016) Consistent estimation in Mendelian randomization with some invalid instruments using a weighted median estimator. Genet Epidemiol 40:304-314

21. Burgess S, Thompson SG (2017) Interpreting findings from Mendelian randomization using the MR-Egger method. Eur J Epidemiol 32:377-389

22. Verbanck M, Chen CY, Neale B, Do R (2018) Detection of widespread horizontal pleiotropy in causal relationships inferred from Mendelian randomization between complex traits and diseases. Nat Genet 50:693-698

23. Rees JMB, Wood AM, Burgess S (2017) Extending the MREgger method for multivariable Mendelian randomization to correct for both measured and unmeasured pleiotropy. Stat Med $36: 4705-4718$

24. Hallstrom H, Byberg L, Glynn A, Lemming EW, Wolk A, Michaelsson K (2013) Long-term coffee consumption in relation to fracture risk and bone mineral density in women. Am J Epidemiol 178:898-909

25. Spiller W, Davies NM, Palmer TM (2017) Software Application Profile: mrrobust-a tool for performing two-sample summary Mendelian randomization analyses. Int J epidemiology 48:684-690

26. Yavorska OO, Burgess S (2017) MendelianRandomization: an R package for performing Mendelian randomization analyses using summarized data. Int J Epidemiol 46:1734-1739

27. Brion MJ, Shakhbazov K, Visscher PM (2013) Calculating statistical power in Mendelian randomization studies. Int J Epidemiol 42:1497-1501

28. Shen GS, Li Y, Zhao G, Zhou HB, Xie ZG, Xu W, Chen HN, Dong QR, Xu YJ (2015) Cigarette smoking and risk of hip fracture in women: a meta-analysis of prospective cohort studies. Injury 46:1333-1340

29. Abu-Amer Y (2013) NF-kappaB signaling and bone resorption. Osteoporos Int 24:2377-2386

30. Sorensen LT, Toft BG, Rygaard J, Ladelund S, Paddon M, James T, Taylor R, Gottrup F (2010) Effect of smoking, smoking cessation, and nicotine patch on wound dimension, vitamin C, and systemic markers of collagen metabolism. Surgery 148:982-990

31. Ma L, Zheng LW, Sham MH, Cheung LK (2010) Uncoupled angiogenesis and osteogenesis in nicotine-compromised bone healing. J Bone Miner Res 25:1305-1313

32. Behfarnia P, Saied-Moallemi Z, Javanmard SH, Naseri R (2016) Serum, saliva, and GCF concentration of RANKL and osteoprotegerin in smokers versus nonsmokers with chronic periodontitis. Adv Biomed Res 5:80

33. Campos JM, Prati AJ, Cirano FR, Pimentel SP, Pastore GP, Pecorari VG, Ribeiro FV, Casati MZ, Casarin RC (2015) Smoking modulates gene expression of type I collagen, bone sialoprotein, and osteocalcin in human alveolar bone. J Oral Maxillofac Surg 73:2123-2131

34. Seibel MJ (2005) Biochemical markers of bone turnover: part I: biochemistry and variability. Clin Biochem Rev 26:97-122

35. Sloan A, Hussain I, Maqsood M, Eremin O, El-Sheemy M (2010) The effects of smoking on fracture healing. Surgeon 8:111-116

36. d'Herbomez M, Caron P, Bauters C, Do Cao C, Schlienger JL, Sapin R, Baldet L, Carnaille B, Wemeau JL (2007) Reference range of serum calcitonin levels in humans: influence of calcitonin assays, sex, age, and cigarette smoking. Eur J Endocrinol 157:749-755

37. Lee DR, Lee J, Rota M, Ahn HS, Park SM, Shin D (2014) Coffee consumption and risk of fractures: a systematic review and doseresponse meta-analysis. Bone 63:20-28

38. Yoon V, Maalouf NM, Sakhaee K (2012) The effects of smoking on bone metabolism. Osteoporos Int 23:2081-2092

39. Thorin MH, Wihlborg A, Akesson K, Gerdhem P (2016) Smoking, smoking cessation, and fracture risk in elderly women followed for 10 years. Osteoporos Int 27:249-255

Publisher's Note Springer Nature remains neutral with regard to jurisdictional claims in published maps and institutional affiliations. 